\title{
Corrosion Resistance Test of Stainless Steels in the Biofuel Environment
}

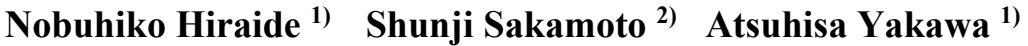 \\ 1) Nippon Steel \& Sumikin Stainless Steel Co. \\ 3434 Shimata, Hikari, Yamaguchi, 743-8550, Japan \\ (E-mail: hiraide.nobuhiko.7fe@nssc.nssmc.com) \\ 1-8-2 Marunouchi, Chiyoda, Tokyo, 100-0005, Japan \\ 2) Nippon Steel \& Sumikin Technology Co. \\ 2-1 Tobihata, Tobata, Kita-kyushu, Fukuoka, 804-0001, Japan
}

Received on October 16, 2018

\begin{abstract}
The oxidation degradation characteristics of four types of bioethanol fuel and one type of biodiesel fuel were investigated. It was found that rape methyl ester (RME) was the fuel that was most susceptive to oxidative degradation, whereas bioethanol fuels were resistant. Oxidative degradation of the fuels promoted the formation of fatty acids in the water phase. Once all formic and acetic acid contained in the oxidized RME was distributed in $0.1 \mathrm{vol} \%$ of the water phase, its $\mathrm{pH}$ was estimated to be $\sim 1.6$. Of the different stainless steel variants in the corrosion tests, which simulated the most severe conditions, SUS436L and SUS444 exhibited excellent corrosion resistance
\end{abstract}

KEY WORDS: materials, stainless steel, corrosion / ferritic, bioethanol, biodiesel, oxidative degradation [D3]

\section{Introduction}

Biofuel is a renewable energy that is an effective substitute for fossil fuels; it is used worldwide, mainly for automobiles. Biofuels typically consist of either bioethanol mixed with ethanol and gasoline, or biodiesel mixed with fatty acid methyl ester (FAME) and diesel oil. FAME is obtained by subjecting vegetable oil to transesterification with methanol; examples of the vegetable oils used include palm oil, rapeseed oil, sunflower oil, and soybean oil. When ethanol is used for bioethanol fuels, substances such as corn and sugar cane are used as raw materials; most biofuels are made from food products.

Various investigations have been conducted to promote the use of biofuels for automobiles, focusing on topics such as fuel characteristics, exhaust gas, and its influence on fuel system members ${ }^{(1-6)}$. Abe et al. reported that ethanol mixed with gasoline had a lower oxidation stability and produced more formic acid and acetic acid than gasoline alone. They also reported that steel was not corroded during a corrosion test carried out using ethanol mixed with gasoline after oxidation treatment ${ }^{(1)}$. Tsuchida reported on the corrosion of aluminum in alcohol and its corrosion reaction mechanism ${ }^{(3)}$. Shiotani et al. conducted a cyclic corrosion test to concentrate the fuel in supply tank by 10 times in order to investigate the degradation of biodiesel fuels ${ }^{(4)}$. They found that FAME mixed with diesel oil had a lower oxidation stability than diesel oil alone. They also found that fatty acids produced by the oxidative degradation of fuel adversely affected the corrosion resistance of coated steel based on simulated corrosion tests.

Stainless Steel displays excellent corrosion resistance, and has traditionally been considered to be resistant to corrosion from biofuels.. However, recent studies have reported that corrosion occurred in $11 \% \mathrm{Cr}$ steel (the minimum $\mathrm{Cr}$ content for stainless steel) when exposed to bio-oil ${ }^{(7)}$ and formic acid ${ }^{(8)}$. While many ferritic stainless steels are used for exhaust system and fuel supply system components, there are few reports on the corrosion resistance of ferritic stainless steels to biofuels. In this study, the oxidation degradation characteristics of various biofuels were investigated, and simulated corrosion test conditions were selected based on the results. The corrosion resistance of six kinds of ferritic stainless steels, and one kind of austenitic stainless steel, were evaluated under these test conditions.

\section{Experimental Design}

\subsection{Fuel}

The fuels used for analysis and testing were as follows:

(1) Gasoline mixed with $10 \%$ bioethanol (E10), US

(2) Gasoline mixed with $22 \%$ bioethanol (E22), Brazil

(3) Gasoline mixed with $85 \%$ bioethanol (E85), US

(4) $100 \%$ bioethanol (E100), Brazil

(5) RME, Germany

(6) Gasoline, Japan

(7) Diesel oil, Japan

\subsection{Oxidation test}

$0.5 \mathrm{~L}$ of each fuel was placed in a $1.42 \mathrm{~L}$ autoclave and filled with $7 \mathrm{~atm} \mathrm{O}_{2}$. The fuel was then heated at $373 \mathrm{~K}$ for 24 hours. These tests were conducted according to JIS K 2287.

\subsection{Analysis method}


The metal components, water, fatty acids, alcohols, and the Total Acid Number (TAN) of each fuel were examined both before and after the oxidation tests. The content of the metal components was measured by inductively coupled plasma optical emission spectrometry (ICP/OES). The water content was measured according to the coulometric Karl Fischer titration method (JIS K 2275). The fatty acids (formic acid, acetic acid, and propionic acid) and alcohols were measured by gas chromatography. The TAN was measured according to JIS K 2501.

Fuel samples from before the oxidation tests were then extracted into water at room temperature. The anions and cations of the water phase were measured by ion chromatography. Samples were then taken of each fuel from after the oxidation tests; these were extracted into water at room temperature. Each fuel and water mixture was shaken for 2 hours in the separating funnel to distribute the water-soluble component in the oil phase to the water phase; the oil phase and the water phase were then separated. The fatty acids of the water phase were measured by ion chromatography. TAN and $\mathrm{pH}$ of the water phase were also measured.

\subsection{Corrosion test}

Sheets of seven kinds of stainless steel, SUH409L (11Cr-Ti), 13Cr-1Si-Nb steel, SUS430LX (17Cr-Ti), SUS436J1L (17Cr$0.5 \mathrm{Mo}-\mathrm{Ti})$, SUS436L (17Cr-1Mo-Ti), SUS444 (19Cr-2Mo-Nb, Ti), and SUS304 (18Cr-8Ni), were prepared for half-immersion and fuel encapsulation tests. The thicknesses of the sheets varied from $0.8 \mathrm{~mm}$ to $1.2 \mathrm{~mm}$. These six ferritic stainless steels were selected to investigate the effect $\mathrm{Cr}$ and $\mathrm{Mo}$ on corrosion resistance and SUS304 was the most versatile austenitic stainless steel.

The half-immersion tests were carried out according to JASO M609-91 Method A. Each specimen was $25 \mathrm{~mm}$ in width and 100 $\mathrm{mm}$ in length. The test solution had a chloride ion concentration of $100 \mathrm{ppm}$, and formic and acetic acid concentrations of 300000 ppm (changed from $10 \mathrm{ppm}$ ). $150 \mathrm{ml}$ of test solution was used for each experiment. Roughly half of the area of each specimen was immersed in the test solution, and the remaining area was exposed to the gas phase. The test temperature was $368 \mathrm{~K}$ and the test period was 168 hours. After the tests, the mass loss due to corrosion and the pit depth were measured.

$\mathrm{RME}$, which was oxidized in $7 \mathrm{~atm} \mathrm{O}_{2}$ at $373 \mathrm{~K}$ for 24 hours, was used for the fuel encapsulation tests. The RME with $40 \mathrm{~mL}$, together with $4 \mathrm{~mL}$ of water containing $100 \mathrm{ppm}$ chloride ions, was sealed in a cup having an inner diameter of $50 \mathrm{~mm}$. The temperature and time period of each experiment were $363 \mathrm{~K}$ and 384 hours respectively. After the tests, the mass loss due to corrosion from each steel sample was measured, and each sample was examined for pitting corrosion.

\section{Results and Discussion}

\subsection{Analysis of fuels prior to experimentation}

The contents of water and alcohols of the fuels prior to experimentation are shown in Table 1. Among the bioethanol fuels, as the ethanol content increases, the concentration of water and alcohols in the fuels also increases. The water content was about $7 \%$ and the alcohol concentration was several thousand ppm in E100. Since the water was in a solvated state, it was considered that it wouldn't affect corrosion. RME featured methanol and ethanol at a concentration of $\sim 100 \mathrm{ppm}$.

The amount of fatty acids and TAN in the fuels prior to experimentation are shown in Table 2. RME contained trace amounts of acetic acid, which slightly increased its TAN. Fatty acids were not detected in bioethanol fuels or gasoline.

Metal components were not detected in any of the fuels. Anions and cations were not detected in the water phase after extraction, except for very small amounts of ammonium ions and sulfate ions in E100.

Table 1 The content of water and alcohols in fuels prior to experimentation

\begin{tabular}{|c|c|c|c|c|c|c|c|}
\hline & E-10 & E-22 & E-85 & E-100 & RME & gasoline & light oil \\
\hline $\begin{array}{c}\text { water } \\
(\mathrm{mg} / \mathrm{kg})\end{array}$ & 980 & 1780 & 6320 & 71560 & 330 & 50 & 80 \\
\hline $\begin{array}{c}\mathrm{methanol}(\mathrm{mg} / \mathrm{kg}) \\
(\mathrm{m})\end{array}$ & $<0.1$ & $<0.1$ & 110 & 360 & 120 & $<1$ & $<1$ \\
\hline $\begin{array}{c}\text { ethanol } \\
(\mathrm{mg} / \mathrm{kg})\end{array}$ & $*$ & $*$ & $*$ & $*$ & 140 & 15 & 9.4 \\
\hline $\begin{array}{c}\mathrm{propanol} \\
(\mathrm{mg} / \mathrm{kg})\end{array}$ & 110 & 180 & 440 & 2900 & $<2$ & $<1$ & $<1$ \\
\hline $\begin{array}{c}\text { isobutanol } \\
(\mathrm{mg} / \mathrm{kg})\end{array}$ & $<1$ & $<1$ & 370 & 550 & $<2$ & $<1$ & $<1$ \\
\hline
\end{tabular}

Table 2 The amount of fatty acids and total acid number in fuels prior to experimentation

\begin{tabular}{|c|c|c|c|c|c|c|c|}
\hline & E10 & E22 & E85 & E100 & RME & gasoline & light oil \\
\hline $\begin{array}{c}\text { formic acid } \\
\text { (mg/kg) }\end{array}$ & $<10$ & $<10$ & $<10$ & $<10$ & $<20$ & $<20$ & $<20$ \\
\hline $\begin{array}{c}\text { acetic acid } \\
\text { (mg/kg) }\end{array}$ & $<1$ & $<1$ & $<1$ & $<1$ & 27 & $<1$ & 25 \\
\hline $\begin{array}{c}\text { propionic acid } \\
\text { (mg/kg) }\end{array}$ & $<1$ & $<1$ & $<1$ & $<1$ & $<1$ & $<1$ & $<1$ \\
\hline $\begin{array}{c}\text { total acid value } \\
\text { (mg-KOH/kg) }\end{array}$ & 0.03 & 0.01 & 0.02 & 0.01 & 0.10 & 0.02 & 0.02 \\
\hline
\end{tabular}

\subsection{Oxidative degradation of fuel}

The time dependence of pressure during each oxidation test is shown in Figure 1. Here decreases in pressure indicate the oxidation of fuel. The pressure drops in E100 and diesel oil were both very small, implying that they were difficult to oxidize. The pressure drops in E10 and E85 were small, while E22, RME, and gasoline decreased remarkably in pressure. From the above, it was concluded that RME and gasoline tend to undergo oxidative degradation, whereas bioethanol fuels and diesel oil are resistant to it.

The amount of fatty acids and TAN of each fuel after the oxidation tests are shown in Table 3. E100 did not produce fatty acids, while the fuels composed of bioethanol mixed with gasoline (E10, E22, and E85) produced acetic acid. Diesel oil only produced a small amount of fatty acids, while RME and gasoline both produced large amounts. The fatty acid produced from RME was mainly formic acid; gasoline produced approximately equal amounts of formic acid and acetic acid. 


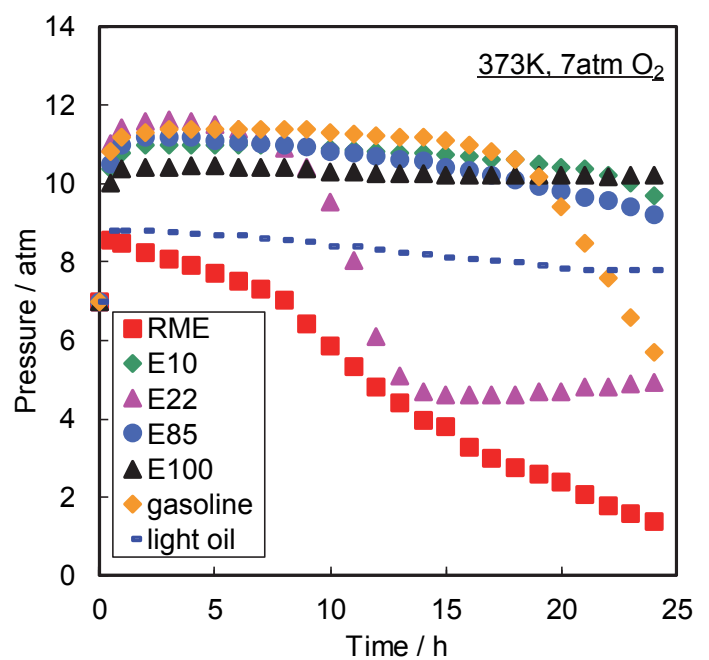

Fig. 1 Time dependence of pressure on the oxidation tests

Table 3 The amount of fatty acids and total acid value after oxidation tests

\begin{tabular}{|c|c|c|c|c|c|c|c|}
\hline & E10 & E22 & E85 & E100 & RME & gasoline & light oil \\
\hline $\begin{array}{c}\text { formic acid } \\
(\mathrm{mg} / \mathrm{kg})\end{array}$ & $<10$ & $<10$ & $<10$ & $<10$ & 4300 & 1100 & $<20$ \\
\hline $\begin{array}{c}\text { acetic acid } \\
(\mathrm{mg} / \mathrm{kg})\end{array}$ & 1600 & 1100 & 3000 & $<1$ & 420 & 1000 & 25 \\
\hline $\begin{array}{c}\text { propionic acid } \\
(\mathrm{mg} / \mathrm{kg})\end{array}$ & 150 & 150 & $<1$ & $<1$ & 340 & 530 & $<1$ \\
\hline $\begin{array}{c}\text { total acid value } \\
(\mathrm{mg}-\mathrm{KOH} / \mathrm{kg})\end{array}$ & 2.82 & 2.33 & 2.89 & 0.05 & 3.75 & 3.75 & 0.25 \\
\hline
\end{tabular}

After the oxidation tests, the fuels were extracted into water at room temperature. The amount of fatty acids, TAN, and $\mathrm{pH}$ in the water phases for each fuel are shown in Table 4 . The volume ratio of the oil phase and the water phase in the table is not unified to avoid emulsification due to the distribution of ethanol over the water phase, and to ensure phase separation.

The fuels containing bioethanol mixed with gasoline produced acetic acid in quantities equal to or more than gasoline alone after the oxidation tests, but the acetic acid contained in the water phase for these fuels after extraction was equal to or less than that for gasoline alone. This observation is attributed to esterification, and to acetic acid staying in the oil phase as ethyl acetate. Formic acid was not detected from the fuels containing bioethanol mixed with gasoline after the oxidation tests, but was detected in their water phases after extraction. This can be explained as follows: formic acid produced by oxidation reacted with ethanol to form ethyl formate. Ethyl formate was hydrolyzed by the extraction and returned to formic acid. The formic acid was then distributed into the water phase.

The amount of fatty acids for RME was different from that for gasoline, but the $\mathrm{pH}$ of the water phase after extraction was equal for both fuels.

Each fuel was mixed with water and was heated in $7 \mathrm{~atm} \mathrm{O}_{2}$ at $323 \mathrm{~K}$ for 24 hours. After heating, each fuel was extracted into water, and the $\mathrm{pH}$ of each water phase was measured. The results are shown in Figure 2. The water phases for E10 and gasoline both showed a neutral $\mathrm{pH}$, whereas RME displayed mild acidity. RME oxidized more easily than gasoline to form fatty acids. It was considered that the bioethanol fuels and gasoline were resistant to oxidative degradation, since gasoline temperature in automobiles was less than $323 \mathrm{~K}$.

Table 4 The amount of fatty acids, total acid value and $\mathrm{pH}$ in water phase after oxidation tests.

\begin{tabular}{|c|c|c|c|c|c|c|}
\hline & E-10 & E-22 & E-85 & RME & gasoline & light oil \\
\hline $\begin{array}{c}\text { ratio between oil } \\
\text { and water }\end{array}$ & $25: 150$ & $25: 150$ & $200: 100$ & $100: 100$ & $100: 100$ & $100: 100$ \\
\hline $\begin{array}{c}\text { formic acid } \\
(\mathrm{mg} / \mathrm{kg})\end{array}$ & $\begin{array}{c}86 \\
<516>\end{array}$ & $\begin{array}{c}63 \\
<378>\end{array}$ & $\begin{array}{c}330 \\
<165>\end{array}$ & 830 & 630 & 33 \\
\hline $\begin{array}{c}\text { acetic acid } \\
(\mathrm{mg} / \mathrm{kg})\end{array}$ & $\begin{array}{c}120 \\
<720>\end{array}$ & $\begin{array}{c}120 \\
<720>\end{array}$ & $\begin{array}{c}1300 \\
<650>\end{array}$ & 320 & 870 & 38 \\
\hline $\begin{array}{c}\mathrm{propionic} \mathrm{acid} \\
(\mathrm{mg} / \mathrm{kg})\end{array}$ & $\begin{array}{c}20 \\
<120>\end{array}$ & $\begin{array}{c}14 \\
<84>\end{array}$ & $\begin{array}{c}33 \\
<17>\end{array}$ & 220 & 170 & 7 \\
\hline $\begin{array}{c}\text { total acid value } \\
(\mathrm{mg}-\mathrm{KOH} / \mathrm{kg})\end{array}$ & $\begin{array}{c}0.30 \\
<1.80>\end{array}$ & $\begin{array}{c}0.42 \\
<2.52>\end{array}$ & $\begin{array}{c}2.06 \\
<1.03>\end{array}$ & 1.74 & 2.17 & 0.02 \\
\hline $\mathrm{pH}$ & 3.0 & 2.9 & 3.2 & 2.4 & 2.4 & 3.2 \\
\hline
\end{tabular}

* The values in $<>$ were obtained by adjusting the volume ratio of the oil phase and the water phase to $1: 1$.

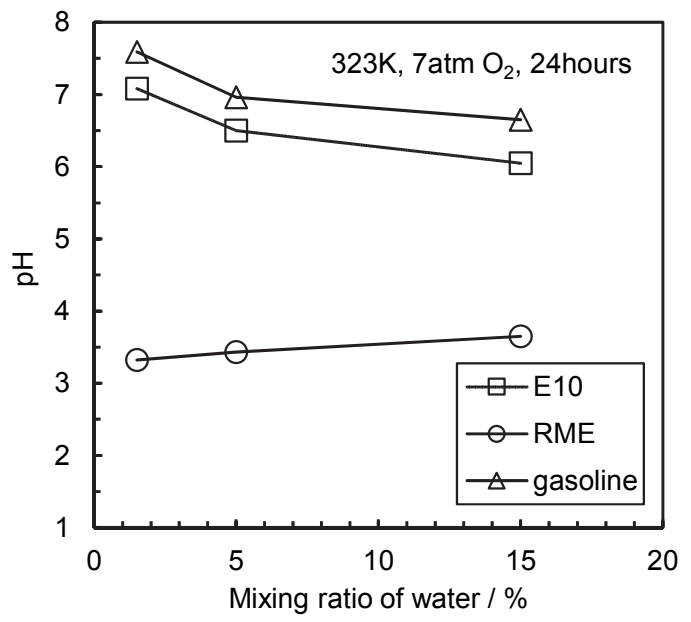

Fig. $2 \mathrm{pH}$ of the water phase after extraction

\subsection{Setting of corrosion test condition}

The $\mathrm{pH}$ of an aqueous solution is one of the most important factors for the corrosion resistance of stainless steels. When fuels are oxidized, fatty acids are produced; these fatty acids are then distributed into the water phase, which lowers its $\mathrm{pH}$. When this occurs, smaller volume ratios of water to fuel will result in higher concentrations of fatty acid, and therefore a lower $\mathrm{pH}$ and a more severe corrosion environment.

Roughly $30 \mathrm{ml}$ of water is needed to measure $\mathrm{pH}$. The smaller the volume ratio of water to fuel, the more fuel is needed, so the experiment becomes more difficult. Therefore, it was decided to obtain the lowest $\mathrm{pH}$, which would produce the most severe corrosion conditions, by theoretical calculation.

As described in the previous section, RME was the most oxidatively degraded of the fuels that were tested. RME was therefore used as a representative example of FAME; it was considered to be effective for determining the most severe corrosion conditions that RME could form. In this study, it was used to generate extremely corrosive conditions, so the final 
corrosion test method may be far too severe than any real-life scenario. However, if any of the stainless steel samples can show corrosion resistance during these conditions, it can be assumed that it has corrosion resistance to FAME in general and, in turn, biodiesel fuel in general.

\subsubsection{Concentration of fatty acid and $\mathrm{pH}$ in the water phase}

When the fatty acid species and their concentrations are known, the $\mathrm{pH}$ of the fatty acid-containing aqueous solution can be calculated based on the equilibrium theory. The relationship between the calculated $\mathrm{pH}$, based on the chemical reaction of the dissociation equilibrium in formic acid, acetic acid, and propionic acid, and the measured $\mathrm{pH}$ is shown in Figure 3. The data in the figure includes date when 15 to $85 \%$ of water is mixed in RME, in addition to the data in Table 4. As shown in the figure, the calculated $\mathrm{pH}$ almost matched the measured $\mathrm{pH}$.

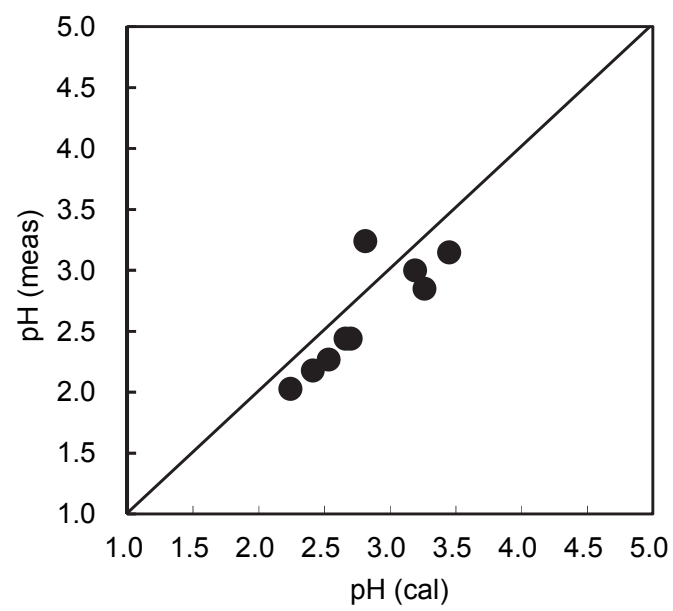

Fig. 3 Relationship between calculated $\mathrm{pH}$ and measured $\mathrm{pH}$

3.3.2. Effect of the volume ratio of water to fuel on the $\mathrm{pH}$ of the water phase

We assumed an extraction equilibrium model in which the oxidized fuel and water are equilibrated. The model is shown in Figure 4 and the equilibrium condition formulae were as follows:

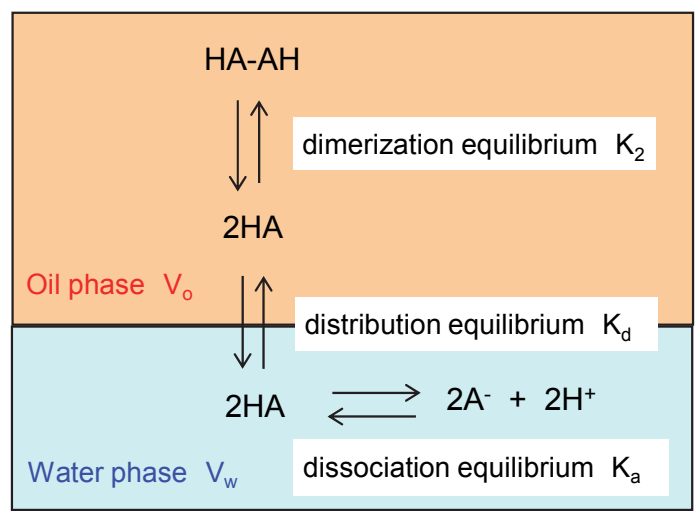

Fig. 4 Extraction model of fatty acid from oil phase to water phase

$$
\begin{aligned}
& K_{2}=\left[(\mathrm{HA})_{2}\right]_{\mathrm{o}} /\left([\mathrm{HA}]_{\mathrm{o}}\right)^{2} \\
& K_{\mathrm{d}}=[\mathrm{HA}]_{\mathrm{w}} /[\mathrm{HA}]_{\mathrm{o}} \\
& K_{\mathrm{a}}=\left[\mathrm{H}^{+}\right]_{\mathrm{w}}\left[\mathrm{A}^{-}\right]_{\mathrm{w}} /[\mathrm{HA}]_{\mathrm{w}} \\
& K_{\mathrm{w}}=\left[\mathrm{H}^{+}\right]_{\mathrm{w}}\left[\mathrm{OH}^{-}\right]_{\mathrm{w}}
\end{aligned}
$$

For electrical neutrality condition in the water phase,

$$
\left[\mathrm{H}^{+}\right]_{\mathrm{w}}=\left[\mathrm{A}^{-}\right]_{\mathrm{w}}+\left[\mathrm{OH}^{-}{ }_{\mathrm{w}}\right.
$$

For substance balance before and after extraction $\mathrm{C} \cdot \mathrm{V}_{\mathrm{o}}=\left\{\left[(\mathrm{HA})_{2}\right]_{\mathrm{o}}+2[\mathrm{HA}]_{\mathrm{o}}\right\} \mathrm{V}_{\mathrm{o}}+2\left\{[\mathrm{HA}]_{\mathrm{w}}+\left[\mathrm{A}^{-}\right]_{\mathrm{w}}\right\} \mathrm{V}_{\mathrm{w}}$

Where $K_{2}$ is the dimerization constant, $K_{\mathrm{d}}$ is the distribution constant, $K_{\mathrm{a}}$ is the dissociation constant, $\mathrm{C}$ is the concentration of fatty acid HA in oxidized fuel, $\mathrm{V}_{\mathrm{o}}$ is the volume of the oil phase, $\mathrm{V}_{\mathrm{w}}$ is the volume of the water phase, $[\mathrm{X}]_{\mathrm{o}}$ is the concentration of chemical species $\mathrm{X}$ in the oil phase and $[\mathrm{X}]_{\mathrm{w}}$ is the concentration of chemical species $\mathrm{X}$ in the water phase.

From formula (1) to formula (6)

$$
\begin{aligned}
& K_{2} /\left(K_{\mathrm{d}} K_{\mathrm{a}}\right)^{2}\left[\mathrm{H}^{+}\right]_{\mathrm{w}}{ }^{4}+2\left\{1 /\left(K_{\mathrm{d}} K_{\mathrm{a}}\right)+1 / K_{a}\left(\mathrm{~V}_{\mathrm{w}} / \mathrm{V}_{\mathrm{o}}\right)-\right. \\
& \left.K_{2} K_{\mathrm{w}} /\left(K_{\mathrm{d}} K_{\mathrm{a}}\right)^{2}\right\}\left[\mathrm{H}^{+}\right]_{\mathrm{w}}{ }^{2}+2\left(\mathrm{~V}_{\mathrm{w}} / \mathrm{V}_{\mathrm{o}}\right)\left[\mathrm{H}^{+}\right]_{\mathrm{w}}-K_{\mathrm{w}}\left(\mathrm{V}_{\mathrm{w}} / \mathrm{V}_{\mathrm{o}}\right) \\
& /\left[\mathrm{H}^{+}\right]_{\mathrm{w}}-\mathrm{C}+K_{2}\left(K_{\mathrm{w}} / K_{\mathrm{d}} K_{\mathrm{a}}\right)^{2}-2 K_{\mathrm{w}} /\left(K_{\mathrm{d}} K_{\mathrm{a}}\right)-2 K_{\mathrm{w}} \\
& / K_{\mathrm{a}}\left(\mathrm{V}_{\mathrm{w}} / \mathrm{V}_{\mathrm{o}}\right)=0
\end{aligned}
$$

Formula (7) was solved for $\left[\mathrm{H}^{+}\right]_{\mathrm{w}}$ after assigning representative values to $K_{2}, K_{\mathrm{d}}$, and $K_{\mathrm{a}}$. The dimerization constant of acetic acid in benzene was used for $K_{2}\left(10^{-2}\right)$, the distribution constant of benzene / acetic acid system was used for $K_{\mathrm{d}}\left(10^{2}\right)$, the dissociation constant of acetic acid in aqueous solution was used for $K_{\mathrm{a}}\left(10^{-5}\right)$, and the ion product of water was used for $K_{\mathrm{w}}\left(10^{-14}\right)$. Figure 5 shows the relationship of the volume ratio of water to fuel by converting the $\left[\mathrm{H}^{+}\right]_{\mathrm{w}}$ into $\mathrm{pH}$. The $\mathrm{pH}$ of the water phase had a linear relationship with the logarithm of the volume ratio of water to fuel. Therefore, it is possible to estimate the lowest $\mathrm{pH}$ by extrapolating to the limit of the volume ratio of water to fuel that causes two-phase separation, based on the $\mathrm{pH}$ measured in the experiment.

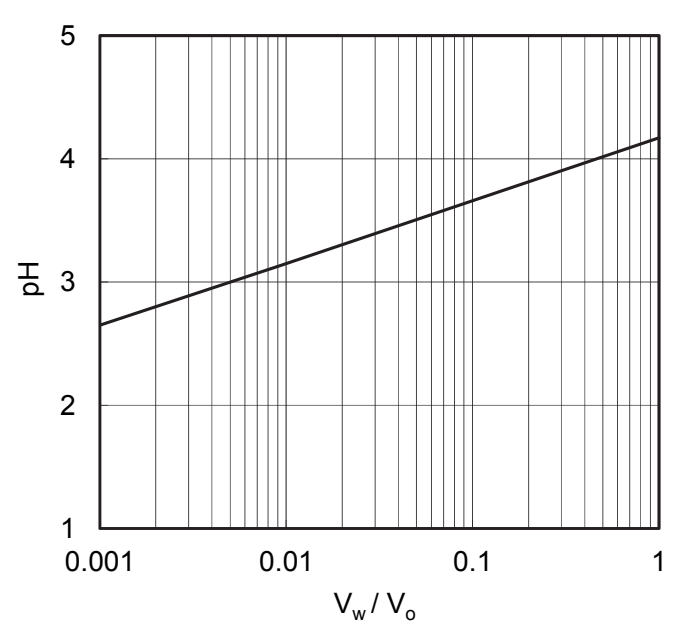

Fig. 5 Effect of pH on the volume ratio of water to fuel 


\subsubsection{Estimation of the lowest $\mathrm{pH}$ of the water phase}

Craig reported that mild steel corroded at a water content of $0.2 \%$, as a result of investigation by varying the content of water in diesel oil ${ }^{(9)}$. Nishikawa reported that two phase separation occurred at a water content of $0.1 \%$ in gasoline mixed with $3 \%$ ethanol at room temperature ${ }^{(10)}$. As shown in Table 1, RME has a water content of about $0.03 \%$ in an emulsion state. Therefore, an intermediate water content between $0.03 \%$ and $0.2 \%$ is considered the boundary between emulsion and two-phase separation. For the purposes of this study, this boundary was taken to be $0.1 \%$.

The $\mathrm{pH}$ was calculated based on the concentration of the fatty acids produced when 15 to $85 \%$ of water is mixed in RME and extrapolated to a volume ratio of water to fuel of 0.001 . The results are shown in Figure 6. The lowest estimated $\mathrm{pH}$ of the water phase was about 1.6. At this time, the formic acid had a concentration of several tens of thousands ppm and the acetic acid had a concentration of several thousand ppm.

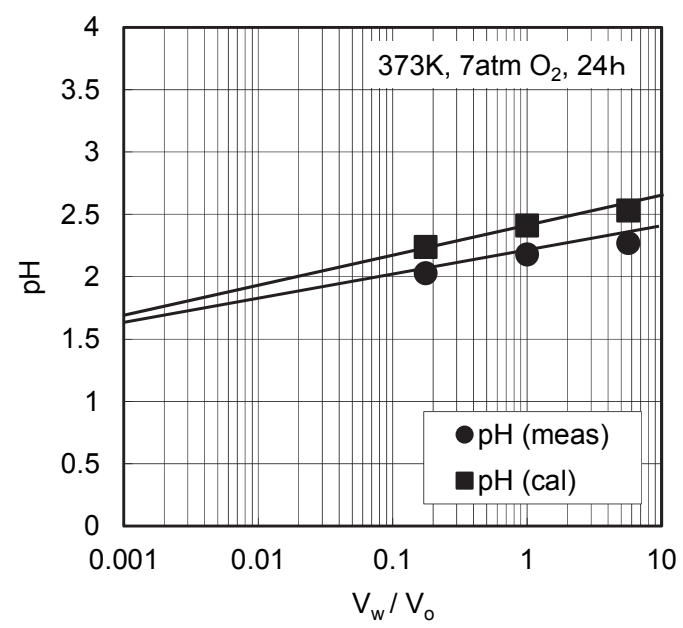

Fig. 6 The estimated $\mathrm{pH}$ of the water phase in RME

\subsubsection{Selection of corrosion test method}

In real environment, the liquid phase and the gas phase coexist. In the liquid phase, the fuel and the condensed water are in phase separation. The gas phase consists of vapor from the fuel and condensed water; part of it is condensed. The half-immersion tests were deemed to be suitable for simulating such a state. The $\mathrm{pH}$ of the test solution was changed from 3.8 to 1.3 by changing the concentration of the formic and acetic acid. Chloride ions were not originally present in the fuel, but were added at a concentration of $100 \mathrm{ppm}$ to promote local corrosion. Considering that the fuel in diesel vehicles reaches temperatures of 353 to 363 $\mathrm{K}$, the temperature of a test solution was set to $368 \mathrm{~K}$, which is somewhat higher.

\subsection{Corrosion test}

The results of the half-immersion tests for each stainless steel sample are shown in Figure 7. Each stainless steel sample was either judged to be "OK" (when pitting corrosion did not occur and mass loss from corrosion was $1 \mathrm{mg}$ or less), or "NG" (when pitting corrosion occurred or mass loss from corrosion exceeded $1 \mathrm{mg}$ ). From Figure 7, the corrosion-resistant limit $\mathrm{pH}$ (measured $\mathrm{pH}$ ) of each stainless steel sample was as follows:

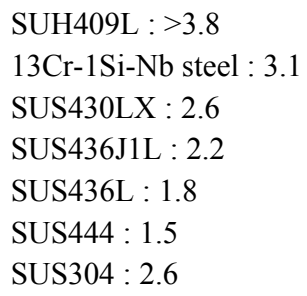

The results show that that the corrosion-resistant limit $\mathrm{pH}$ decreased according to the pitting index $(\mathrm{Cr}+3.3 \mathrm{Mo})$ of each steel type.

It is possible to calculate $\mathrm{pH}$ using the concentration of formic acid and acetic acid, making it possible to create a usage limit map for each steel type using its corrosion-resistant limit $\mathrm{pH}$. An example of the calculation results is shown in Figure 8.

The appearance of the bottom of each cup-shaped specimen after the fuel encapsulation test is shown in Figure 9. Pitting corrosion was observed at the bottom of the specimen for SUS430LX, but corrosion was not observed in SUS436L and SUS444. Since the volume ratio of water to fuel was 0.1 , the $\mathrm{pH}$ of the water phase in the test was estimated to be $\sim 2.0$ from Figure 5. The results of the fuel encapsulation test corresponded to the corrosion-resistant limit $\mathrm{pH}$ values obtained in the halfimmersion tests.

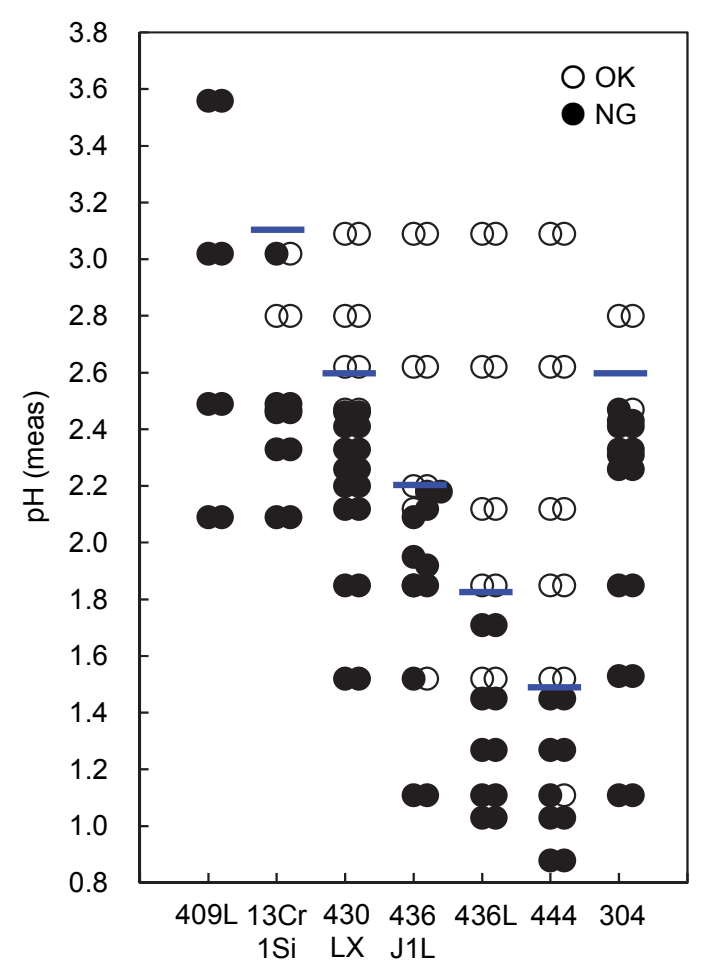

Fig. 7 The results of the half-immersion tests 


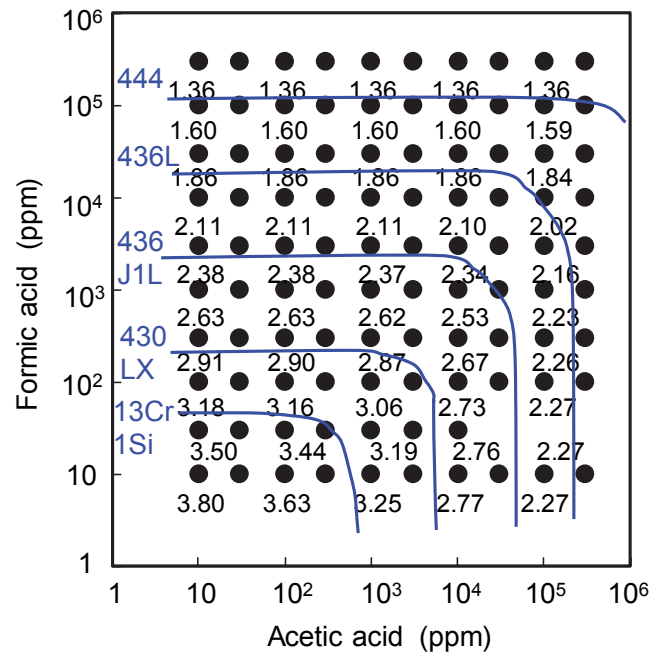

Fig. 8 Limit map for each steel type using its corresponding corrosion-resistant limit $\mathrm{pH}$

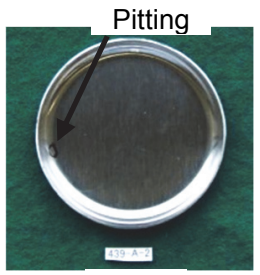

$430 L X$

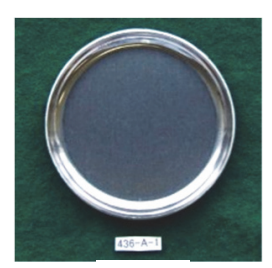

$436 \mathrm{~L}$

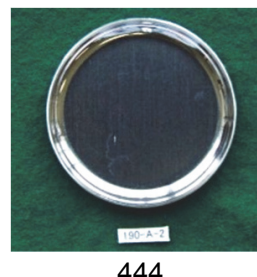

444
Fig. 9 The appearance of the bottom of the cup-shaped specimen after the fuel encapsulation test

\section{Conclusion}

The oxidation degradation characteristics of four kinds of bioethanol fuels and one kind of biodiesel fuel were investigated, and simulated corrosion test conditions were selected based on the results. Under these test conditions, the corrosion resistance of six kinds of ferritic stainless steels and one kind of austenitic stainless steel was evaluated.

During oxidation tests in $7 \mathrm{~atm} \mathrm{O}_{2}$ at $373 \mathrm{~K}$ for 24 hours, RME underwent the most oxidative degradation, whereas bioethanol fuels were resistant to oxidative degradation. The oxidative degradation of the fuels promoted the formation of fatty acids, such as formic acid and acetic acid, in the water phase after extraction, lowering the water phase's $\mathrm{pH}$.

Once all formic acid and acetic acid contained in the oxidized RME was distributed to 0.1 vol\% of the water phase, its $\mathrm{pH}$ was estimated to be $\sim 1.6$. This condition was the most severe, and corresponded to about $10 \%$ of the total concentration of formic acid and acetic acid. Based on these results, a mixed aqueous solution of formic acid and acetic acid whose $\mathrm{pH}$ was changed from 2.8 to 1.3 was used for the simulated corrosion test; chloride ions (100 ppm) were also added to promote local corrosion.

Half-immersion tests were carried out at $368 \mathrm{~K}$ using the above solution, revealing the corrosion-resistant limit $\mathrm{pH}$ of each stainless steel. The results revealed that SUS436L and SUS444 exhibit good corrosion resistance under the most severe conditions. These steels also showed excellent corrosion resistance in the fuel encapsulation test, which was performed at $363 \mathrm{~K}$; this test involved using oxidized RME and water containing $100 \mathrm{ppm}$ chloride ions with a volume ratio of water to fuel of 0.1 .

( This paper is written based on a proceeding presented at JSAE 2018 Annual Congress )

\section{References}

(1) Rie Abe, Toshinori Mizuguchi : Oxidation Behavior of Ethanol Fuel and HS Corrosivity, CAMP-ISIJ, Vol.7, p.1542 (1994).

(2) Yukio Akasaka : Performance of Ethanol-blended Gasoline : Jounal of Society of Automotive Engineers of Japan, Vol.58, No.11, pp.23-27 (2004).

(3) Takashi Tsuchida : Corrosion Behavior of Aluminum by Mixed Alcohol Solutions : Zairyo-to-Kankyo, Vol.53, No.1, pp.44-49 (2004).

(4) Hitoshi Shiotani, Shinichi Goto, Takashi

Hoshino : Applicability Investigation of Biodiesel Fuel for Automotive Fuel : Jounal of Society of Automotive Engineers of Japan, Vol.60, No.1, pp.94-99 (2006).

(5) Kenji Nomoto : Evaluation on Influence of Water Contamination on Ethanol-blended Gasoline : Jounal of Society of Automotive Engineers of Japan, Vol.61, No.11, pp.55-60 (2007).

(6) Seiji Takai : Standard for E10 Gasoline Motor Vehicles and E10 Fuel Specifications : Jounal of Society of Automotive Engineers of Japan, Vol.65, No.11, pp.44-48 (2011).

(7) J. R. Keiser, M. P. Brady, S. A. Lewis, Sr, R. M. Connaster, D. N. Leonard, I. Whitmer : Impact of Corrosion on Selection of Structural Materials for Thermochemical Processing of Biomass : CD only Proceedings of the TAPPI PEERS Conference, Sept. 14-17, 2014 Tacoma WA USA.

(8) Mari Miyoseta : Effect of Alloying Element to Martensitic Stainless Steel on Corrosion Resistance to Formic Acid, Sanyo Technical Report, Vol.23, No.1, pp.62-67 (2016)

(9) Bruce Craig : Algorithm of Simple Rules for the Critical Water Content of Crude Oil and Condensate, MCI Technical Report, 0616-97-3987-0577, (1997).

(10) Teruhiko Nishikawa : A Practical Use of Bio-fuel for Cars, Doryoku, No.269, pp.1-9, (2007). 